\title{
Cervical human papillomavirus infection and squamous intraepithelial lesions in rural Gambia, West Africa: viral sequence analysis and epidemiology
}

\section{SR Wall*, I,6,8, CF Scherf ${ }^{2,6}$, L Morison ${ }^{3}$, KW Hart ${ }^{2}$, B West ${ }^{4}$, G Ekpo ${ }^{4}$, AN Fiander ${ }^{2}$, S Man', CM Gelder', G Walraven $^{4,7}$ and LK Borysiewicz ${ }^{5}$}

'Infection \& Immunity, Henry Wellcome Research Institute, Wales College of Medicine, Cardiff University, Cardiff CFI 4 4XX, Wales, UK; ${ }^{2}$ Obstetrics \& Gynaecology, Wales College of Medicine, Cardiff University, Cardiff CFI 4 4XN, Wales, UK; ${ }^{3}$ London School of Hygiene \& Tropical Medicine, London WCIE 7HT, UK; ${ }^{4}$ MRC Laboratories Farafenni, PO Box 273, Banjul, The Gambia; ${ }^{5}$ Imperial College, London SW7 2AZ, UK

The development of effective strategies against cervical cancer in Africa requires accurate type specific data on human papillomavirus (HPV) prevalence, including determination of DNA sequences in order to maximise local vaccine efficacy. We have investigated cervical HPV infection and squamous intraepithelial lesions (SIL) in an unselected cohort of I06I women in a rural Gambian community. Squamous intraepithelial lesions was diagnosed using cytology and histology, HPV was typed by PCR-ELISA of DNA extracts, which were also DNA sequenced. The prevalence of cervical HPV infection was 13\% and SIL were observed in 7\% of subjects. Human papillomavirus- 16 was most prevalent and most strongly associated with SIL. Also common were HPV-I8, -33, -58 and, notably, -35. Human papillomavirus DNA sequencing revealed HPV-I6 samples to be exclusively African type I (AfI). Subjects of the Wolof ethnic group had a lower prevalence of HPV infection while subjects aged 25-44 years had a higher prevalence of cervical precancer than older or younger subjects. This first report of HPV prevalence in an unselected, unscreened rural population confirms high rates of SIL and HPV infection in West Africa. This study has implications for the vaccination of Gambian and other African populations in the prevention of cervical cancer.

British Journal of Cancer (2005) 93, 1068 - 1076. doi:I0.1038/sj.bjc.6602736 www.bjcancer.com

Published online II October 2005

(c) 2005 Cancer Research UK

Keywords: HPV; SIL; DNA sequence; unselected; rural; Africa; vaccination

It is well established, on a cellular and epidemiological basis, that the sexual transmission of high oncogenic risk (HR) human papillomavirus (HPV) types is the essential prerequisite for cervical carcinogenesis (zur Hausen, 1977; IARC_Monographs, 1995; Muñoz and Bosch, 1996; Walboomers et al, 1999). Cervical cancer is the most common malignancy in West African women (Koulibaly et al, 1997; Bah et al, 2001) but accurate, population-based HPV prevalence data are lacking. Many therapeutic and prophylactic vaccines against HPV infection are in development, with some now entering phase III trials (Bosch et al, 2001; Nardelli-Haefliger et al, 2003; Taira, 2004; Tomson et al, 2004; Christensen, 2005; Gravitt and Shah, 2005; Maclean et al, 2005). Such vaccines are essential in developing countries where $80 \%$ of new cervical cancer cases occur but where screening and treatment of precancerous lesions is not available (Kitchener and Symonds, 1999; Lazcano-Ponce et al, 1999).

*Correspondence: Dr SR Wall; E-mail: wallsr@cf.ac.uk

${ }^{6}$ These authors contributed equally to this work.

${ }^{7}$ Current address: Secretariat de Son Altesse l'Aga Khan, Aiglemont, 60270 Gouvieux, France.

${ }^{8}$ Current address: Department of Child Health, Wales College of Medicine, Cardiff University, 5th Floor University Hospital of Wales, Heath Park, Cardiff, CFI4 4XN, Wales, UK.

Received 18 May 2005; revised 29 June 2005; accepted 6 July 2005; published online II October 2005
Risk factors in the spread of genital HPV infection vary between populations, and include genetic variation in human leukocyte antigen (HLA) types resulting in differential susceptibility to HPV infection and socio-demographic factors such as sexual behaviour or age (Burk et al, 1996; Koutsky, 1997; Svare et al, 1998; Herrero, 1999). Consequently, prevalence of cervical cancer in industrialised nations cannot be assumed to apply in the developing world; local characterisation of HPV patterns is essential. Human papillomavirus-16 is the most prevalent type in cervical cancers worldwide (Bosch et al, 1995b), although regional variation in HR HPV types does occur (Bosch et al, 1995a; Herrero et al, 2000; Castellsague et al, 2001; Mayaud et al, 2001; Xi et al, 2003). HPV DNA sequence must therefore be defined to ensure vaccine efficacy and prevent the selective emergence of rare, virulent variants. Here we describe such detailed HPV analysis in a rural Gambian community, presenting the largest point-prevalence study to date in a rural unselected sub-Saharan African population.

\section{METHODS}

\section{Population}

Samples were collected during a large reproductive morbidity survey in rural Gambia between January and July 1999 as described elsewhere (Walraven et al, 2001). Briefly, the MRC has 
run a continuous demographic surveillance system in 40 villages surrounding the provincial town of Farafenni since 1981. All women aged 15-54 years in 20 of these villages were approached and invited to participate. The study was approved by the ethics committee of The Gambian Government/MRC Laboratories (SCC proposal 755). All work was conducted in accordance with the Helsinki Declaration of 1975 as revised in 1983. After obtaining informed consent. A total of 1348 women ( $72 \%$ of those eligible) were seen and examined in dedicated village clinics.

\section{Sampling}

As part of the full gynaecological assessment, all consenting subjects who did not have an intact hymen underwent a vaginal speculum examination (Figure 1). Cervical smears were taken with an Aylesbury spatula for cytology (Wolfendale et al, 1987) fixed, stored and transported to Cardiff. Human papillomavirus sampling was performed by inserting the brush-sampler into the cervical canal and rotating it through $360^{\circ}$. This brush was placed in transport medium immediately (Digene Corporation, Gaithersburg, MD, USA), stored at $-70^{\circ} \mathrm{C}$ and frozen samples transported to Cardiff for analysis.

\section{Cytology}

Women with abnormalities were offered further assessment and treatment with Large Loop Excision of the Transformation Zone (LLETZ) or knife cone biopsy. Histology and cytology results

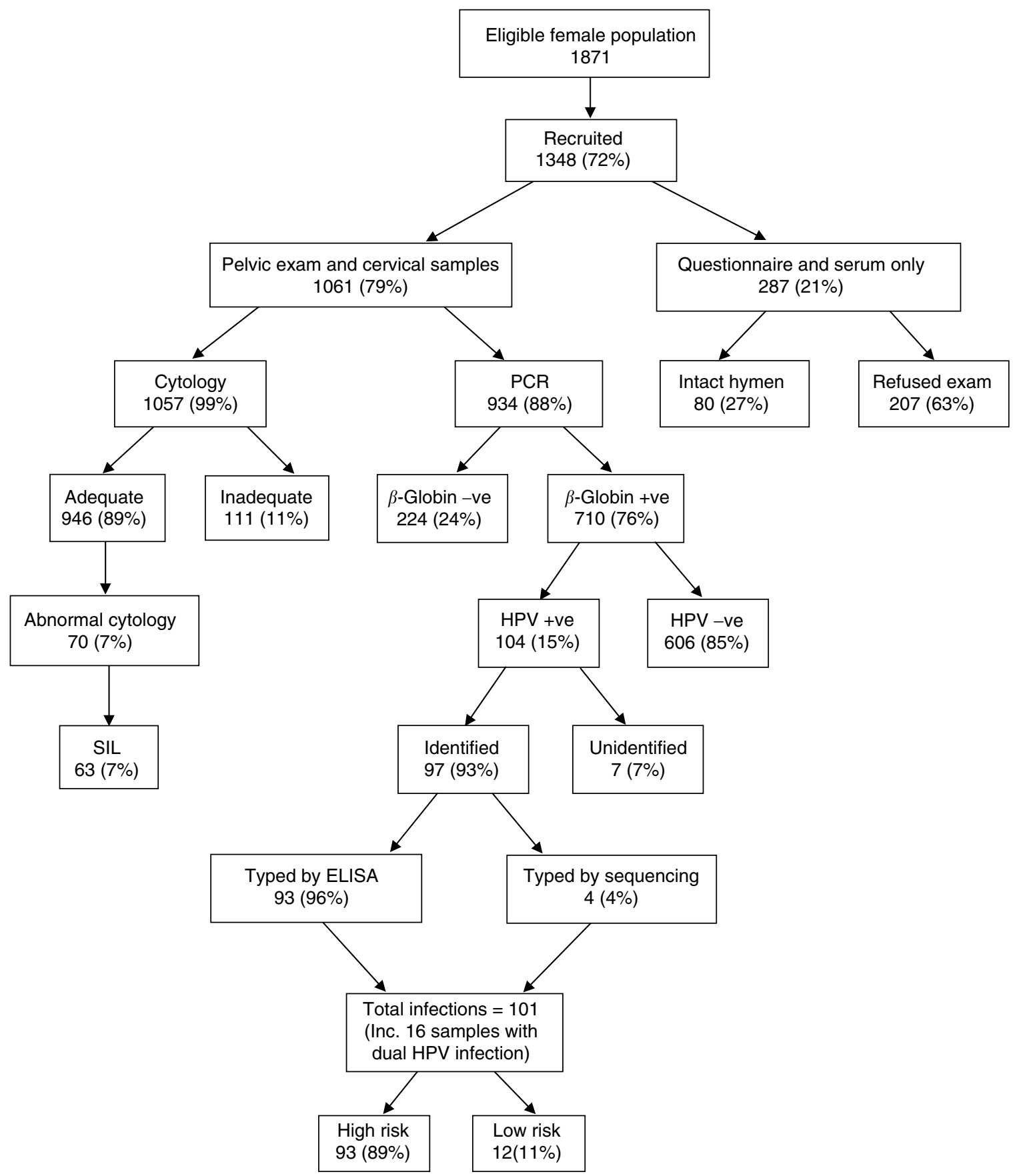

Figure I Overview of gambia reproductive morbidity study. 
were subjected to clinical review to decide on a final diagnosis viz low- or high-grade squamous intraepithelial lesions (LSIL or HSIL) (NCI_Workshop, 1989), microinvasive or invasive carcinoma of the cervix.

\section{Human papillomavirus detection and typing}

DNA was extracted from cervical brush samples by freeze-thaw from $-70^{\circ} \mathrm{C}$, boiling for $10 \mathrm{~min}$ followed by rapid cooling on ice. Human papillomavirus DNA was detected by PCR using the consensus HPV primers GP5 + and GP6 + (biotinylated) (Jacobs et al, 1997). In tandem, for each sample a PCR was also set up to amplify the human $\beta$-globin gene in order to verify the presence of an adequate DNA sample and the absence of PCR inhibitors. The presence of HPV and $\beta$-globin DNA was visualised on an agarose gel. Human papillomavirus typing was preformed by enzyme linked immuno-sorbent assay (ELISA) using streptavidin coated microtitre plates to capture PCR product (Jacobs et al, 1997). Initially, this involved two cocktails of digoxigenin labelled probes, the first including those types commonly associated with cervical cancer (HPV-16, -18, -31, -33, -35, -39, -45, -51, -52, -56, -58, -59, -66 and -68$)$. The second cocktail included those types associated with benign genital lesions (HPV-6, -11, -40,-42,-43 and -44). Detection was performed using an alkaline phosphatase conjugated antidigoxigenin fab fragment. If positive for either of the two probes, a further ELISA was performed using the full spectrum of relevant (HR) or low risk (LR) individual probes.

\section{Sequencing}

Samples that could not be identified by ELISA were characterised by DNA sequencing. Selected HPV positive samples were also sequenced to confirm typing accuracy and to detect any relevant sequence variations in known HPV types. Sequencing was carried out on a Beckman Coulter CEQ2000 Automated Sequencer, using protocols and reagents supplied by the manufacturer. Human papillomavirus DNA sequencing utilised the MY09/MY11 consensus primer pair as the product of these $(\approx 455 \mathrm{bp})$ is a more suitable target for sequencing than that of GP5 $+16+(\approx 140 \mathrm{bp})$. Furthermore, MY09/11 primers amplify a region containing highly conserved amino acids, which simplifies sequence alignment in HPV classification (Chan et al, 1995). An NCBI BLAST (http:// www.ncbi.nlm.nih.gov/BLAST/) search was carried out for each of the consensus strands produced by sequencing at least twice in each direction. Alignment analysis was carried out using the Lasergene suit of software (DNA* Inc., Madison, WI, USA). The sequences most homologous to the Gambia samples are listed in Table 2 with the percentage DNA similarity and number of differences in both amino acids (coding) and DNA only (noncoding) in the MY9/11 amplified region between the Gambia samples and the closest BLAST hits.

\section{Statistical analysis}

All data were double-entered, checked and cleaned using Epi-Info 6.4 with subsequent analysis performed in STATA 7 (Statacorp. Texas). Frequency distributions of HPV infection and different HPV types were calculated. Socio-demographic characteristics and other morbidities were examined as risk factors for HPV infection by cross tabulation and $\chi^{2}$ tests. To adjust for any confounding effects, each potential risk factor was included in a logistic regression model with age group, marital status and ethnic group. The same procedure was followed for SIL. There were significant differences in the distribution of ethnic groups between the sample and the eligible population and differing disease prevalence between ethnic groups (Table 1). An adjusted prevalence was therefore calculated using the prevalence within each ethnic group and the distribution of ethnic groups in the eligible population.

\section{RESULTS}

Of 1871 eligible women, 1348 (72\%) participated in the study (Figure 1) and 1061 women consented to full gynaecological examination. Of participants aged 15-24 years, 30.7\% (147 out of 478) were unmarried, 80 of whom consented to intimate examination and had an intact hymen (Figure 1). These women were not examined internally by speculum and no cervical specimen was collected. No HPV sample was taken from a further 64 women examined by speculum and 63 samples were lost in transit. The $\beta$-globin human housekeeping gene was amplified in 710 out of $934(76 \%)$ samples; consequently, only these samples were suitable for HPV analysis. The $\beta$-globin negative samples may have been incorrectly stored or damaged during transfer to the $\mathrm{UK}$, prevalence figures are therefore based upon the $710 \beta$-globin positive samples. Of the three main ethnic groups, Wolof women were slightly under-represented $(38.7 \%$ of eligible population $v s$ $32.1 \%$ of those with adequate cytology and $34.1 \%$ of those with adequate HPV samples) and Mandinka women were slightly over-represented ( $43.9 \%$ of eligible population $v s 49.5 \%$ of those with adequate cytology and $46.2 \%$ of those with adequate HPV samples). Younger women aged 15-24 years were underrepresented (27.9 and $25.9 \%$ in those with adequate cytology and adequate HPV samples, respectively, compared with $39.1 \%$ in the eligible population).

\section{Human papillomavirus prevalence}

Human papillomavirus infection was present in 95 of 710 adequate samples (crude prevalence $13.4 \%$ (95\% CI: 10.96-16.11\%)). Adjusting HPV prevalence for under-representation of Wolof subjects reduced prevalence slightly to $13.0 \%$. Human papillomavirus typing by PCR-ELISA was successful in 84 samples revealing 6 different LR and 13 different HR types (Figure 2). Dual cervical HPV infection was found in 16 subjects. HPV-16 (21 out of 109 (19\%)) and HPV-35 (11 out of $109(10 \%)$ were most common. Other prevalent types were HPV-18, -33 and -58 (each 9/109 (8\%)), HPV-31 (8/109 (7\%)) and HPV-42 (6/109 (6\%)).

\section{DNA sequencing}

Human papillomavirus DNA was amplified with the GP5 + $/ 6+$ primers in 11 samples but were negative by ELISA, and therefore contained HPV types not included in the probe cocktails. These samples were sequenced with the MY 09/11 primers; five had either degenerated in storage or would not amplify, two contained multiple templates and were impossible to sequence, while four were successfully sequenced and identified but none were infected with novel types, merely types not included in the ELISA probe cocktail (Table 2).

DNA sequencing was conducted on samples successfully identified by ELISA as HPV types associated with HSIL. All HPV-16 samples sequenced showed DNA homology in the amplified region with a variant of HPV-16 African type 1 (Af1, Accession No. AF536180) (Table 2). Both HPV-18 samples sequenced displayed protein sequence homology to HPV-18 variants from Benin, West Africa (Accession Nos. U45894 and U45892) (Table 2). HPV-31 from our study showed a number of polymorphisms and silent mutations compared to the reference sequence (Accession No. J04353), but insufficient to be a novel type (Bernard, 2005) (Table 2). All HPV-33 samples sequenced displayed protein sequence homology to the reference HPV-33 strain (Accession No. M12732) (Table 2). The sequence of HPV-58 
Table I Association between cervical HPV infection and socio-demographic, behavioural and infectious factors in the Gambia Reproductive Morbidity Study

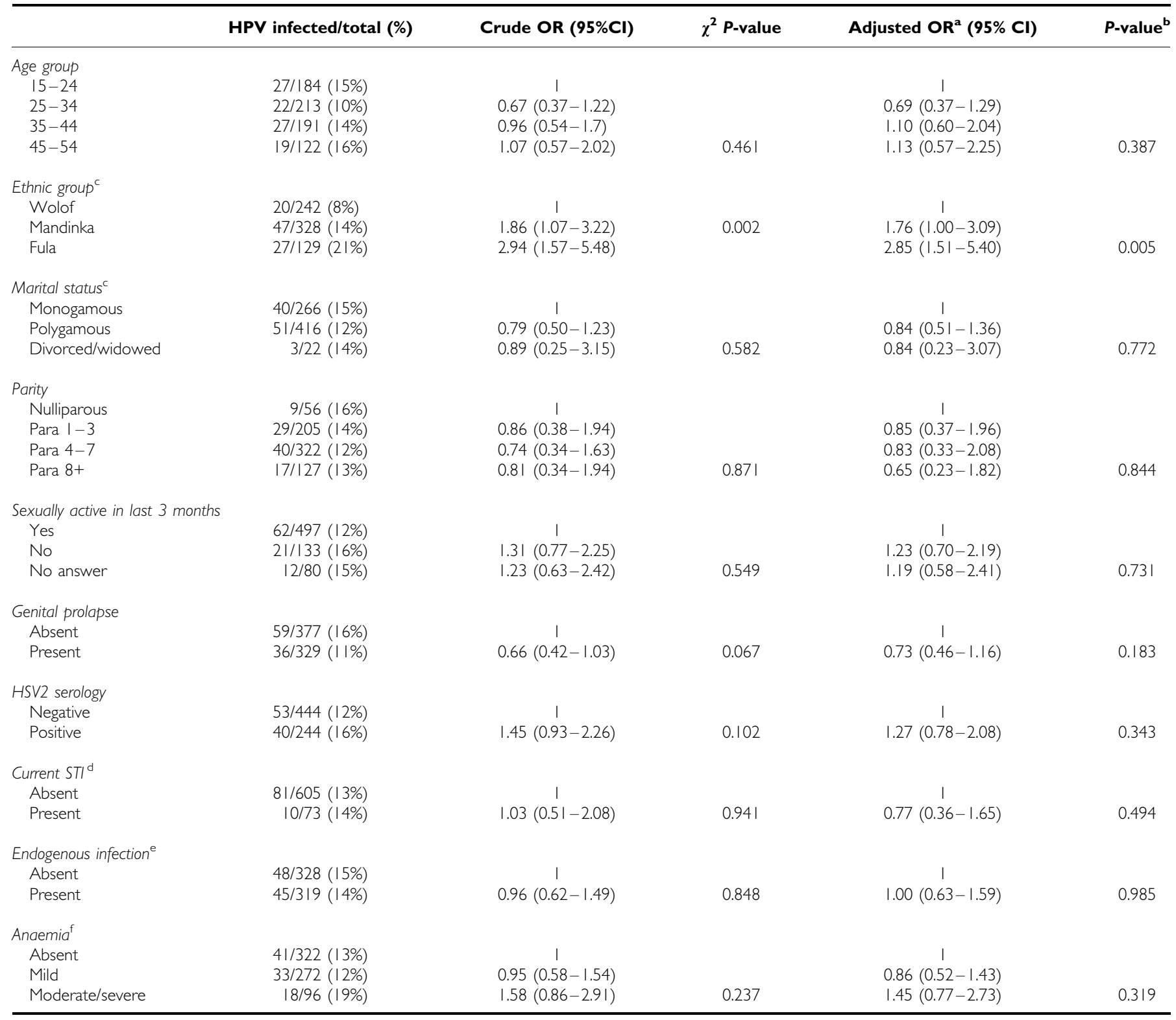

${ }^{a}$ Adjusted for age group, marital status and ethnic group. ${ }^{b}$ From likelihood ratio test adjusting for age group, marital status and ethnic group. ${ }^{\mathrm{C}}$ Five single women (one had HPV) and II women of other ethnic groups (one had HPV) were excluded from this analysis because of small numbers. ${ }^{\mathrm{d} C h l a m y d i a}$ trachomatis, Trichomonas vaginalis, positive Syphilis serology. ${ }^{~}{ }^{2}$ Candida culture positive, Bacterial vaginosis (Nugent's criteria). ${ }^{f}$ Anaemia: mild $=\mathrm{Hb}<\mathrm{II}$ (pregnant) $\mathrm{Hb}<12$ (nonpregnant), moderate/severe $=\mathrm{Hb}<9$ (pregnant), $\mathrm{Hb}<10$ (nonpregnant).

from our study was identical to a variant isolated in the West African nation of Mali (Table 2).

\section{Cytology and histology}

The overall crude prevalence of cervical precancer was $6.7 \%$ (63/ 946 adequate smears (95\% CI: $5.2-8.4 \%)$ ), or $6.5 \%$ after adjusting for the under-representation of Wolof women Cytological abnormalities were confirmed by histology in 55.6\% (35/63) of cases with HSIL present in $2.3 \%(n=22 ; 16$ confirmed by histology), LSIL were found in $3.3 \%$ ( $n=31 ; 19$ confirmed by histology) and atypical squamous cells of uncertain significance (ASCUS) in $1.1 \%(n=10)$. A single case of invasive cervical cancer was diagnosed by clinical and cytological criteria but the woman sadly died before the histology could be confirmed; it was included in the HSIL analysis.

\section{Epidemiology}

Risk factors for cervical precancer included age $\left(\chi^{2} P=0.03\right)$ and cervical HPV infection. Rates of SIL were highest at ages 25-34 years (22 out of $265(8 \%))$ and 35-44 years (24/268 (9\%)), intermediate at ages 45-54 (9/150 (6\%)) and lowest at ages 15-24 $(8 / 263(3 \%))$. In subjects where both adequate cytology/histology and HPV analysis were available, 574/612 (93\%) had normal cytology, 38 out of $612(6 \%)$ had SIL and seven out of $612(1 \%)$ had ASCUS. Of the subjects with normal cytology 525/574 (91\%) were negative for HPV while in those with SIL/ASCUS 20/38 (53\%) had 


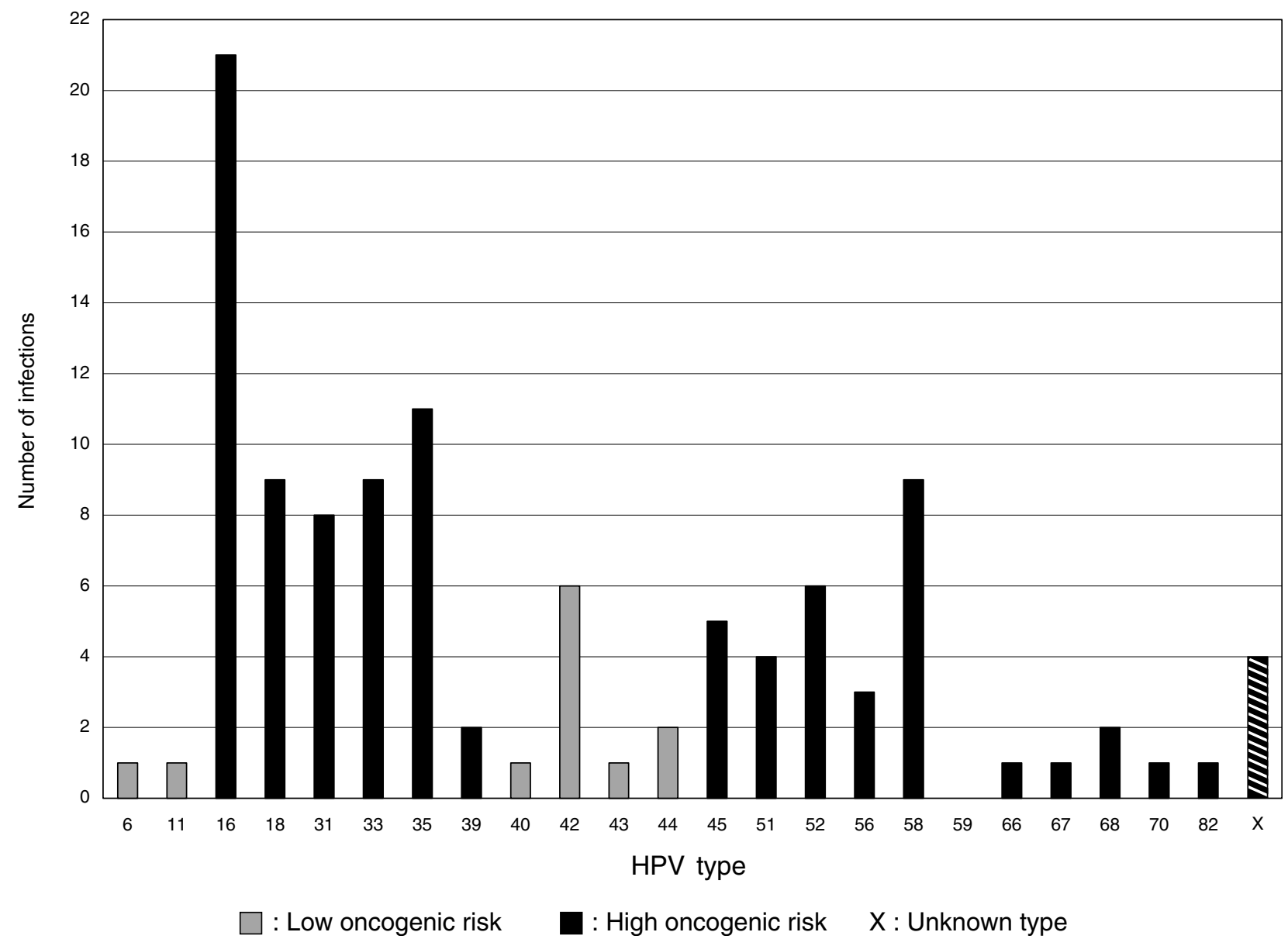

Figure 2 Total of all HPV types (inc. multiple infections).

HR HPV types. Of subjects with HSIL, 13/15 (87\%) had HR HPV types, although the other two were negative for HPV. Among subjects with HSIL, HPV-16, HPV-33 and HPV-58 were most common, each found in $3 / 15$ (20\%). HPV-16 was found in the single invasive cancer case. HPV-18, $-31,-35,-39$ and -45 occurred once each among subjects with HSIL. Of 30 subjects with LSIL/ ASCUS, seven were infected with HR HPV types; of subjects with normal cytology 66/576 (12\%) had HPV infection.

No associations were found between HPV and other current sexually transmitted infections (STI) (Table 1). Moderate or severe anaemia was associated with HPV infection, but not significantly. Similarly, abnormal vaginal bleeding or discharge, pelvic masses and body mass index showed no significant associations with HPV infection. Of 1110 subjects, only $61(6 \%)$ used modern methods of contraception, too few to examine associations with HPV. Among socio-demographic factors, only the subject's ethnic origin was significantly associated with HPV infection, with Mandinka (14\%) and Fula $(21 \%)$ women having a higher risk of cervical HPV infection than Wolof subjects $(8 \%)$ (Table 1$)$.

\section{DISCUSSION}

This first unselected study of cervical HPV and SIL in an unscreened, rural West-African population of its kind shows HPV infection to be common at $13.4 \%$ (adjusted $=13.0 \%$ ) with the majority HR types. Although younger subjects were underrepresented, such an age profile is comparable with other studies. The high cervical HPV infection prevalence and SIL are in agreement with Gambian Cancer Registry data (Koulibaly et al, 1997; Bah et al, 2001). Comparable prevalences of $14 \%$ have been observed in two cytologically normal populations in Senegal, the only nation on which The Gambia borders (Astori et al, 1999; Xi et al, 2003). A recent study from Nigeria, West Africa, of an unselected population of similar size typed by GP5 +1 $6+$ PCR-ELISA, found an HPV prevalence of $26 \%$ (Thomas et al, 2004). However, the population in Thomas et al was urban (Ibadan, pop. $>1 \mathrm{M}$ ) and the higher HPV prevalence may be explained by differing sexual behaviour as well as the much higher prevalence of LR HPV types in the Nigerian study than in our study.

Much higher HPV prevalence figures have been reported in recent unselected studies from Eastern and Southern Africa, ranging from $34 \%$ in rural Zimbabwe (Baay et al, 2004) to $44 \%$ in urban Kenya (De Vuyst et al, 2003). Human immunodeficiency virus (HIV) infection and concomitant immune suppression is an acknowledged cofactor in the progression of cervical cancer (Feingold et al, 1990; Moscicki et al, 2004a, b) and such high HPV prevalence may be due to the high rates of HIV infection in these regions (UNAIDS, 2004). The Gambia has one of the lowest HIV infection rates in Africa (Ramsay, 1993, [73]Da Costa, 1994; Schim van der Loeff et al, 2003). Multiple cervical HPV infection is common in Africa (Chabaud et al, 1996; Castellsague et al, 2001; Gravitt et al, 2002; Stanczuk et al, 2003; Xi et al, 2003; Baay et $a l, 2004)$ yet we encountered no more than two co-infections, perhaps because of the low HIV rates in The Gambia (UNAIDS, 2004). Multiple HPV infection have been linked to HIV immunosuppression (Levi et al, 2002a, b; Moscicki et al, 2004a) 
Table 2 Genetic comparison of HPV DNA sequences in the Gambia Reproductive Morbidity Study compared to closest Genbank entries

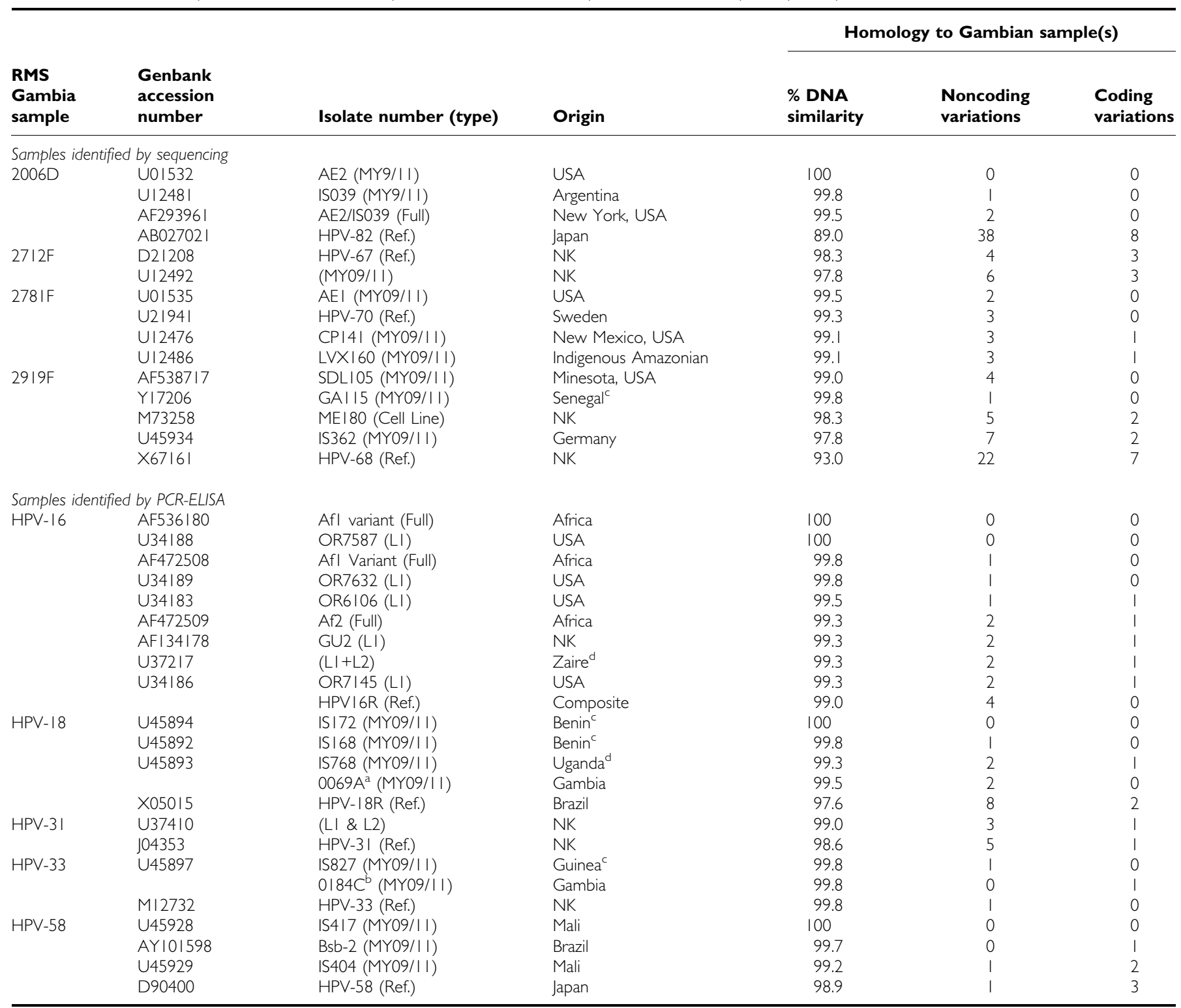

${ }^{a}$ Sample from this study differing in two noncoding bases from the other HPV- 18 samples sequenced. ${ }^{b}$ Sample from this study differing in one coding base from the other HPV33 samples sequenced. 'West Africa. ${ }^{d}$ Central Africa.

and in Zimbabwean HIV infected individuals may exhibit quintuple HPV infection (Baay et al, 2004).

High oncogenic risk HPV can be detected in $>99.7 \%$ of highgrade pre-invasive and invasive cervical lesions (Walboomers et al, 1999). In this study, HPV was found in $87 \%$ of subjects with high-grade lesions, indicating a high degree of accuracy for HPV detection. Failure to detect HPV in two subjects with HSIL may be due to integration of viral DNA into their genomic DNA and the consequent deletion of the target site for the consensus PCR primers. HPV shows a wide type distribution (Figure 2) (eight types associated with HSIL), but an even distribution among subjects. HPV-16, the most common HR type worldwide (Bosch, 1995a, b; Muñoz et al, 2003) is the most common type in this study, showing the strongest association with precancer.

The HR type HPV-35 was the second most prevalent type (10\%) in this study and meta-analysis of worldwide HPV prevalence studies shows low overall prevalence of HPV-35 $(\approx 2 \%)$, even in
Africa (Clifford et al, 2003b). Three selective urban Senegalese studies found a very low prevalence of HPV-35 ranging from no HPV-35 positive samples (Astori et al, 1999; Chabaud et al, 1996) to $1 \%$ in the most recent (Xi et al, 2003). Inconsistency between studies examining Senegal and Gambian populations with overlapping ethnic groups, religious practices and trade routes initially appears incongruous. However, the GP5 $+/ 6+$ primers used in the Gambian study are estimated to be 5000 times more sensitive in the detection of HPV-35 (Qu et al, 1997) than the MY09/MY11 primer pair used in the $\mathrm{Xi}$ and Astori studies. Therefore, the true HPV-35 prevalence in these Senegalese studies is likely to have been underestimated. This is supported by other African studies where HPV-35 is among the four of the most prevalent types in studies not exclusively using the MY09/11 primer pair for HPV typing (Castellsague et al, 2001; De Vuyst et al, 2003; Baay et al, 2004; Naucler et al, 2004; Thomas et al, 2004). The Nigerian population displays a similar distribution of HR types to the 
Gambian except that HPV-16 and -35 are jointly the most prevalent types in Nigerian study (Thomas et al, 2004). It thus appears that HPV-35 is prevalent throughout sub-Saharan Africa but the extent of this prevalence is underestimated by the use of the MY09/11 primer pair. This indicates the importance of methodology in the design of viral epidemiological studies. Of the $13 \%(12 / 93)$ of samples positive for LR HPV, HPV-42 was most prevalent, accounting for $50 \%$ of LR types and $6 \%$ of all HPV types. This is in contrast to the USA and Europe where HPV-6 and HPV-11 are the dominant LR types (Muñoz et al, 2003) and most other African studies, where HPV-53 and -54 are the dominant LR types (Castellsague et al, 2001; De Vuyst et al, 2003; Xi et al, 2003). HPV-42 was the most prevalent LR type and overall the most common HPV type in Nigeria (Thomas et al, 2004), increasing the overall HPV prevalence, with a LR:HR HPV ratio of 35:65 compared to $11: 89$ in our Gambian study.

Human papillomavirus is classified into types, subtypes and variants by comparative DNA homology based upon the L1 outer capsid. To define a new HPV type it must have less than $90 \% \mathrm{~L} 1$ DNA homology to any previously defined types. Human papillomavirus types can be further characterised into subtypes, $90-98 \%$ L1 DNA homology, and variants (either $>98 \%$ L1 DNA homology or oncogene variations). No HPV samples in this study were found to be novel types after identification by sequencing, although some were unusual subtypes or variants (Table 2). The DNA sequences of HPV $-16,-18,-33$ and -68 revealed HPV variants found by other African studies. In particular, the Gambian HPV-68 samples are an exact DNA match to an HPV-68 subtype first isolated from a study in neighbouring Senegal (Astori et al, 1999). Our study also confirms the importance of HPV-16 Af1, the most prevalent of the HPV-16 subtypes in Africa (Yamada et al, 1997). Gambian HPV-18 and HPV-33 variants are homologous to those found in Benin, Uganda and Guinea (Table 2). Thus, with the non-HPV-16 samples associated with HSIL in this study, a number of polymorphisms are observed compared to the reference types but most are identical or similar to types found in other African studies (Table 2).

Histologically confirmed cervical neoplasia prevalence in our study was $6.7 \%$ (adjusted $=6.5 \%$ ). Diagnostic accuracy was improved by classifying subjects with abnormal cytology but normal histology as 'normal cervix'. The prevalence of abnormal cytology alone was slightly higher at $7.4 \%$ (70/946 adequate smears). Other investigators have used a cytological screening to identify cervical disease providing a less accurate prevalence of SIL (Herrero et al, 2000; Castellsague et al, 2001).

In this study, HPV infection was not associated with age, parity or concurrent STI. The even distribution of HPV prevalence at different ages is unusual though observed in other developing countries such as India (Franceschi, 2005) and Argentina (Matos et al, 2003). Studies from industrialised countries show a high HPV prevalence among women under 25 years declining with age (Sellors et al, 2000; Giuliano et al, 2001). This may be explained by study bias since data are commonly collected from such highly selective populations as college students or clinic attendees.
Our study, however, concerns a nonselective population with minimal migration; differing sexual behaviour in different cultural environments may contribute to the variable age-profiles. Certain ethnicities were associated with higher risk of cervical HPV infection in Gambia, a decreased risk being seen in Wolof women compared with Mandinka and Fula subjects, perhaps due to differing patterns of sexual behaviour. Another possibility is genetic variation in susceptibility to HPV infection, for example, due to differences in HLA types while differences in female genital cutting (FGC) between the ethnic groups suggest a further mechanism. The Wolof are the only ethnic group in our study that do not practice FGC and may thereby be less susceptible to HPV infection. A previous study of this group found lower prevalences of HSV-2 (herpes simplex virus) and bacterial vaginosis among nongenitally cut women (Morison et al, 2001).

The ideal treatment strategy for this rural Gambian population would involve the use of a prophylactic vaccine to prevent cellular viral entry. Current prophylactic vaccine formulations require three needle injections, cold storage and offer only type specific protection (Koutsky et al, 2002; Harper et al, 2004). In rural Gambia with a spread of prevalent HR HPV types, where funding is short supply, this is impractical. However, vaccines currently in development include oral based prophylactic vaccines (Baud et al, 2004; Berg et al, 2005; Sasagawa et al, 2005), which will be easier to store and administer and thus economically viable.

The ethnic groups in our study population have not previously been studied using these methods. Other studies in African populations using the same methods to those used in our study (La Ruche et al, 1998; Bayo et al, 2002; Baay et al, 2004; Naucler et al, 2004; Thomas et al, 2004) show differing LR/HR ratios and disease associations. This suggests that in addition to HPV infection host factors are central in the development of cervical cancer. Our findings strengthen existing data from developing nations, showing widespread cervical HPV infection of a broader spectrum than found in industrialised nations with HPV-16 most common. An effective vaccine for the Gambia must be multivalent and include the other HR types prevalent in this representative rural population including HPV-18, -58 and -33 . HPV-35 was not found in high-grade lesions and evidence for its oncogenicity is limited. However, as the second most prevalent type in this study with close homology to HPV-16, it may be worth including in any potential vaccine.

\section{ACKNOWLEDGEMENTS}

We would like to thank the MRC for funding this project and acknowledge the work of staff at the MRC Farafenni, Gambia. Also, Dr N Dallimore, Llandough Hospital, Vale of Glamorgan, Wales, for his histology work and the Cytology Department Llandough Hospital for examination of cervical smears. In particular, we would like to thank the women of the Gambia, without whom this study would not exist.

\section{REFERENCES}

Astori G, Beltrame A, Pipan C, Raphenon G, Botta GA (1999) PCR-RFLP detected human papilloma virus infection in a group of Senegalese women attending an STD clinic and identification of a new HPV-68 subtype. Intervirology 42: $221-227$

Baay MF, Kjetland EF, Ndhlovu PD, Deschoolmeester V, Mduluza T, Gomo E, Friis H, Midzi N, Gwanzura L, Mason PR, Vermorken JB, Gundersen SG (2004) Human papillomavirus in a rural community in Zimbabwe: the impact of HIV co-infection on HPV genotype distribution. J Med Virol 73: $481-485$
Bah E, Parkin DM, Hall AJ, Jack AD, Whittle H (2001) Cancer in the Gambia: 1988-97. Br J Cancer 84: 1207-1214

Baud D, Ponci F, Bobst M, De Grandi P, Nardelli-Haefliger D (2004) Improved efficiency of a Salmonella-based vaccine against human papillomavirus type 16 virus-like particles achieved by using a codonoptimized version of L1. J Virol 78: $12901-12909$

Bayo S, Bosch FX, de Sanjose S, Munoz N, Combita AL, Coursaget P, Diaz M, Dolo A, van den Brule AJ, Meijer CJ (2002) Risk factors of invasive cervical cancer in Mali. Int J Epidemiol 31: $202-209$ 
Berg M, Difatta J, Hoiczyk E, Schlegel R, Ketner G (2005) Viable adenovirus vaccine prototypes: high-level production of a papillomavirus capsid antigen from the major late transcriptional unit. Proc Natl Acad Sci USA 102: $4590-4595$

Bernard HU (2005) The clinical importance of the nomenclature, evolution and taxonomy of human papillomaviruses. J Clin Virol 32(Supp 1): $1-6$

Bosch FX, Manos MM, Munoz N, Sherman M, Jansen AM, Peto J, Schiffman MH, Moreno V, Kurman R, Shah KV (1995a) Prevalence of human papillomavirus in cervical cancer: a worldwide perspective. International biological study on cervical cancer (IBSCC) Study Group. J Natl Cancer Inst 87: 796-802

Bosch FX, Manos MM, Muñoz N, Sherman M, Jansen AM, Peto J, Schiffman MH, Moreno V, Kurman R, Shah KV (1995b) Prevalence of human papillomavirus in cervical cancer: a worldwide perspective. International Biological Study on Cervical Cancer (IBSCC) Study Group. J Natl Cancer Inst 87: 796-802

Bosch FX, Muñoz N, de Sanjose S, Franco EL, Lowy DR, Schiffman M, Franceschi S, Kjaer SK, Meijer CJ, Frazer IH, Cuzick J (2001) Re: Cervical carcinoma and human papillomavirus: on the road to preventing a major human cancer. I Natl Cancer Inst 93: 1349-1350

Burk RD, Kelly P, Feldman J, Bromberg J, Vermund SH, DeHovitz JA, Landesman SH (1996) Declining prevalence of cervicovaginal human papillomavirus infection with age is independent of other risk factors. Sex Transm Dis 23: 333-341

Castellsague X, Menendez C, Loscertales MP, Kornegay JR, dos Santos F, Gomez-Olive FX, Lloveras B, Abarca N, Vaz N, Barreto A, Bosch FX, Alonso P (2001) Human papillomavirus genotypes in rural Mozambique. Lancet 358: $1429-1430$

Chabaud M, Le Cann P, Mayelo V, Leboulleux D, Diallo AS, Enogat N, Afoutou JM, Anthonioz P, Coll-Seck AM, Coursaget P (1996) Detection by PCR of human papillomavirus genotypes in cervical lesions of Senegalese women. J Med Virol 49: 259-263

Chan SY, Delius H, Halpern AL, Bernard HU (1995) Analysis of genomic sequences of 95 papillomavirus types: uniting typing, phylogeny, and taxonomy. J Virol 69: 3074-3083

Christensen ND (2005) Emerging human papillomavirus vaccines. Expert Opin Emerg Drugs 10: 5 - 19

Clifford GM, Smith IS, Plummer M, Muñoz N, Franceschi S (2003b) Human papillomavirus types in invasive cervical cancer worldwide: a metaanalysis. Br J Cancer 88: 63-73

Da Costa P (1994) AIDS in the Gambia/Afr Rep/. 39: $52-53$

De Vuyst H, Steyaert S, Van Renterghem L, Claeys P, Muchiri L, Sitati S, Vansteelandt S, Quint W, Kleter B, Van Marck E, Temmerman M (2003) Distribution of human papillomavirus in a family planning population in Nairobi, Kenya. Sex Transm Dis 30: 137-142

Feingold AR, Vermund SH, Burk RD, Kelley KF, Schrager LK, Schreiber K, Munk G, Friedland GH, Klein RS (1990) Cervical cytologic abnormalities and papillomavirus in women infected with human immunodeficiency virus. J Acquir Immune Defic Syndr 3: 896-903

Franceschi S (2005) The IARC commitment to cancer prevention: the example of papillomavirus and cervical cancer. Recent Results Cancer Res 166: $277-297$

Giuliano AR, Papenfuss M, Abrahamsen M, Denman C, de Zapien JG, Henze JL, Ortega L, Brown de Galaz EM, Stephan J, Feng J, Baldwin S, Garcia F, Hatch K (2001) Human papillomavirus infection at the United States-Mexico border: implications for cervical cancer prevention and control. Cancer Epidemiol Biomarkers Prev 10: 1129-1136

Gravitt PE, Kamath AM, Gaffikin L, Chirenje ZM, Womack S, Shah KV (2002) Human papillomavirus genotype prevalence in high-grade squamous intraepithelial lesions and colposcopically normal women from Zimbabwe. Int J Cancer 100: 729-732

Gravitt PE, Shah KV (2005) A virus-based vaccine may prevent cervical cancer. Curr Infect Dis Rep 7: 125-131

Harper DM, Franco EL, Wheeler C, Ferris DG, Jenkins D, Schuind A, Zahaf T, Innis B, Naud P, De Carvalho NS, Roteli-Martins CM, Teixeira J, Blatter MM, Korn AP, Quint W, Dubin G (2004) Efficacy of a bivalent L1 virus-like particle vaccine in prevention of infection with human papillomavirus types 16 and 18 in young women: a randomised controlled trial. Lancet 364: 1757-1765

Herrero R, Hildesheim A, Bratti C, Sherman ME, Hutchinson M, Morales J, Balmaceda I, Greenberg MD, Alfaro M, Burk RD, Wacholder S, Plummer M, Schiffman M (2000) Population-based study of human papillomavirus infection and cervical neoplasia in rural Costa Rica. J Natl Cancer Inst 92: $464-474$
Herrero R, Muños N (1999) Human papilomavirus and cancer. In Infections and Human Cancer, Vol 33. Cancer Surveys, Newton R, Beral V, Weiss RA (eds) New York: Cold Spring Harbor Laboratory Press

IARC_Monographs (1995) Human Papillomavirus Vol 64, IARC Monographs on the Evaluation of the Carcinogenic Risk of Chemicals to Humans, Lyon

Jacobs MV, Snijders PJ, van den Brule AJ, Helmerhorst TJ, Meijer CJ, Walboomers JM (1997) A general primer GP5+/GP6(+)-mediated PCRenzyme immunoassay method for rapid detection of 14 high-risk and 6 low-risk human papillomavirus genotypes in cervical scrapings. J Clin Microbiol 35: 791-795

Kitchener HC, Symonds P (1999) Detection of cervical intraepithelial neoplasia in developing countries. Lancet 353: 856-857

Koulibaly M, Kabba IS, Cisse A, Diallo SB, Diallo MB, Keita N, Camara ND, Diallo MS, Sylla BS, Parkin DM (1997) Cancer incidence in Conakry, Guinea: first results from the Cancer Registry $1992-1995$. Int J Cancer 70: $39-45$

Koutsky L (1997) Epidemiology of genital human papillomavirus infection. Am J Med 102: 3-8

Koutsky LA, Ault KA, Wheeler CM, Brown DR, Barr E, Alvarez FB, Chiacchierini LM, Jansen KU (2002) A controlled trial of a human papillomavirus type 16 vaccine. $N$ Engl J Med 347: 1645-1651

La Ruche G, You B, Mensah-Ado I, Bergeron C, Montcho C, Ramon R, Toure-Coulibaly K, Welffens-Ekra C, Dabis F, Orth G (1998) Human papillomavirus and human immunodeficiency virus infections: relation with cervical dysplasia-neoplasia in African women. Int J Cancer 76: $480-486$

Lazcano-Ponce EC, Moss S, Alonso de Ruiz P, Salmeron Castro J, Hernandez Avila M (1999) Cervical cancer screening in developing countries: why is it ineffective? The case of Mexico. Arch Med Res 30: $240-250$

Levi JE, Fink MC, Canto CL, Carretiero N, Matsubara R, Linhares I, Das Dores GB, Castelo A, Segurado A, Uip DE, Eluf JJ (2002a) Human papillomavirus prevalence, viral load and cervical intraepithelial neoplasia in HIV-infected women. Braz J Infect Dis 6: 129-135

Levi JE, Kleter B, Quint WG, Fink MC, Canto CL, Matsubara R, Linhares I, Segurado A, Vanderborght B, Neto JE, Van Doorn LJ (2002b) High prevalence of human papillomavirus (HPV) infections and high frequency of multiple HPV genotypes in human immunodeficiency virus-infected women in Brazil. J Clin Microbiol 40: $3341-3345$

Maclean J, Rybicki EP, Williamson AL (2005) Vaccination strategies for the prevention of cervical cancer. Expert Rev Anticancer Ther 5: 97-107

Matos E, Loria D, Amestoy GM, Herrera L, Prince MA, Moreno J, Krunfly C, van den Brule AJ, Meijer CJ, Munoz N, Herrero R (2003) Prevalence of human papillomavirus infection among women in Concordia, Argentina: a population-based study. Sex Transm Dis 30: 593-599

Mayaud P, Gill DK, Weiss HA, Uledi E, Kopwe L, Todd J, ka-Gina G, Grosskurth H, Hayes RJ, Mabey DC, Lacey CJ (2001) The interrelation of HIV, cervical human papillomavirus, and neoplasia among antenatal clinic attenders in Tanzania. Sex Transm Infect 77: 248-254

Morison L, Scherf C, Ekpo G, Paine K, West B, Coleman R, Walraven G (2001) The long-term reproductive health consequences of female genital cutting in rural Gambia: a community-based survey. Trop Med Int Health 6: $643-653$

Moscicki AB, Ellenberg JH, Crowley-Nowick P, Darragh TM, Xu J, Fahrat S (2004a) Risk of high-grade squamous intraepithelial lesion in HIVinfected adolescents. J Infect Dis 190: 1413-1421

Moscicki AB, Ellenberg JH, Farhat S, Xu J (2004b) Persistence of human papillomavirus infection in HIV-infected and -uninfected adolescent girls: risk factors and differences, by phylogenetic type. J Infect Dis 190: $37-45$

Muñoz N, Bosch FX (1996) The causal link between HPV and cervical cancer and its implications for prevention of cervical cancer. Bull Pan Am Health Organ 30: 362-377

Muñoz N, Bosch FX, de Sanjose S, Herrero R, Castellsague X, Shah KV, Snijders PJ, Meijer CJ (2003) Epidemiologic classification of human papillomavirus types associated with cervical cancer. $N$ Engl J Med 348: $518-527$

Nardelli-Haefliger D, Wirthner D, Schiller JT, Lowy DR, Hildesheim A, Ponci F, De Grandi P (2003) Specific antibody levels at the cervix during the menstrual cycle of women vaccinated with human papillomavirus 16 virus-like particles. J Natl Cancer Inst 95: 1128-1137

Naucler P, Da Costa FM, Ljungberg O, Bugalho A, Dillner J (2004) Human papillomavirus genotypes in cervical cancers in Mozambique. J Gen Virol 85: $2189-2190$ 
NCI_Workshop (1989) The 1988 Bethesda System for reporting cervical/ vaginal cytological diagnoses. National Cancer Institute Workshop. JAMA 262: $931-934$

Qu W, Jiang G, Cruz Y, Chang CJ, Ho GY, Klein RS, Burk RD (1997) PCR detection of human papillomavirus: comparison between MY09/MY11 and GP5+/GP6+ primer systems. J Clin Microbiol 35: 1304-1310

Ramsay S (1993) HIV, AIDS, and Africa. Lancet 341: 366-367

Sasagawa T, Tani M, Basha W, Rose RC, Tohda H, Giga-Hama Y, Azar KK, Yasuda H, Sakai A, Inoue M (2005) A human papillomavirus type 16 vaccine by oral delivery of L1 protein. Virus Res 110: $81-90$

Schim van der Loeff MF, Sarge-Njie R, Ceesay S, Awasana AA, Jaye P, Sam O, Jaiteh KO, Cubitt D, Milligan P, Whittle HC (2003) Regional differences in HIV trends in The Gambia: results from sentinel surveillance among pregnant women. AIDS 17: 1841-1846

Sellors JW, Mahony JB, Kaczorowski J, Lytwyn A, Bangura H, Chong S, Lorincz A, Dalby DM, Janjusevic V, Keller JL (2000) Prevalence and predictors of human papillomavirus infection in women in Ontario, Canada. Survey of HPV in Ontario Women (SHOW) Group. CMAJ 163: $503-508$

Stanczuk GA, Kay P, Sibanda E, Allan B, Chirara M, Tswana SA, Bergstrom S, Williamson AL (2003) Typing of human papillomavirus in Zimbabwean patients with invasive cancer of the uterine cervix. Acta Obstet Gynecol Scand 82: $762-766$

Svare EI, Kjaer SK, Worm AM, Osterlind A, Moi H, Christensen RB, Meijer CJ, Walboomers JM, van den Brule AJ (1998) Risk factors for HPV infection in women from sexually transmitted disease clinics: comparison between two areas with different cervical cancer incidence. Int $J$ Cancer 75: $1-8$

Taira AV (2004) Evaluating human papillomavirus vaccination programs. Emerg Infect Dis 10: 1915-1923

Thomas JO, Herrero R, Omigbodun AA, Ojemakinde K, Ajayi IO, Fawole A, Oladepo O, Smith JS, Arslan A, Munoz N, Snijders PJ, Meijer CJ,
Franceschi S (2004) Prevalence of papillomavirus infection in women in Ibadan, Nigeria: a population-based study. Br J Cancer 90: 638-645

Tomson TT, Roden RB, Wu TC (2004) Human papillomavirus vaccines for the prevention and treatment of cervical cancer. Curr Opin Invest Drugs 5: $1247-1261$

UNAIDS (2004) 2004 Report on the Global AIDS epidemic. Joint United Nations Programme on HIV/AIDS (UNAIDS), Geneva

Walboomers JM, de Roda Husmann AM, van den Brule AJ, Snijders PJ, Meijer CJ (1995) Detection of genital human papillomavirus infections: critical review or methods and prevalence studies in relation to cervical cancer. In Human Papillomaviruses and Cervical Cancer: Biology and Immunology, Stern PL, Stanley MA (eds) pp 41-71. Oxford: Oxford University Press

Walboomers JM, Jacobs MV, Manos MM, Bosch FX, Kummer JA, Shah KV Snijders PJ, Peto J, Meijer CJ, Muñoz N (1999) Human papillomavirus is a necessary cause of invasive cervical cancer worldwide. J Pathol 189: $12-19$

Walraven G, Scherf C, West B, Ekpo G, Paine K, Coleman R, Bailey R, Morison L (2001) The burden of reproductive-organ disease in rural women in The Gambia, West Africa. Lancet 357: 1161-1167

Wolfendale MR, Howe-Guest R, Usherwood MM, Draper GJ (1987) Controlled trial of a new cervical spatula. Br Med J (Clin Res Edn) 294: $33-35$

Xi LF, Toure P, Critchlow CW, Hawes SE, Dembele B, Sow PS, Kiviat NB (2003) Prevalence of specific types of human papillomavirus and cervical squamous intraepithelial lesions in consecutive, previously unscreened, West-African women over 35 years of age. Int J Cancer 103: 803-809

Yamada T, Manos MM, Peto J, Greer CE, Muñoz N, Bosch FX, Wheeler CM (1997) Human papillomavirus type 16 sequence variation in cervical cancers: a worldwide perspective. J Virol 71: 2463-2472

zur Hausen H (1977) Human papillomaviruses and their possible role in squamous cell carcinomas. Curr Top Microbiol Immunol 78: 1-30 